\title{
Modified Usage of Negative Pressure Wound Therapy for the Management of Severe Deep Fascial Space Infections in the Head and Neck
}

This article was published in the following Dove Press journal: Infection and Drug Resistance

\author{
Jian Cao ${ }^{1,2, *}$ \\ Zhixu Liu',* \\ Dongyang $\mathrm{Ma}^{2}$ \\ Shunyao Shen' \\ Xudong Wang' \\ 'Department of Oral and \\ Craniomaxillofacial Surgery, Shanghai \\ Ninth People's Hospital, College of \\ Stomatology, Shanghai JiaoTong \\ University School of Medicine; National \\ Clinical Research Center for Oral \\ Diseases; Shanghai Key Laboratory of \\ Stomatology \& Shanghai Research \\ Institute of Stomatology, Shanghai, \\ People's Republic of China; ${ }^{2}$ Department \\ of Oral and Maxillofacial Surgery, The \\ 940th Hospital of People's Liberation \\ Army, Lanzhou, People's Republic of \\ China
}

*These authors contributed equally to this work
Correspondence: Xudong Wang

Department of Oral and

Craniomaxillofacial Surgery, Shanghai

Ninth People's Hospital, College of

Stomatology, Shanghai JiaoTong University

School of Medicine; National Clinical

Research Center for Oral Diseases;

Shanghai Key Laboratory of Stomatology

\& Shanghai Research Institute of

Stomatology, 639 Zhizaoju Road, Shanghai

2000 I I, People's Republic of China

Tel +862153315159

Email xudongwang70@hotmail.com
Purpose: Although negative pressure wound therapy (NPWT) has been widely used in complicated wound care, there are still some obstacles regarding its use in the treatment of severe deep fascial space infections in the head and neck. The purpose of this study is to describe a new modified usage of NPWT and investigate the clinical efficacy of this system in a consecutive case series of severe deep fascial space infections.

Methods: The investigators implemented a new modification of NPWT for the management of severe deep fascial space infections. In this new system, the half-plugged bar-shaped foam material was arranged along with the through-and-through side-holed latex drainage tube, which could maintain negative pressure in the distal part of the spaces, and the tube was easy to remove 5-7 days after surgery. Twelve patients had severe deep fascial space infections in the head and neck with a direct threat to the airway. The median time of removal of the NPWT device, the median amount of drainage fluid and the median healing time were investigated.

Results: A total of 7 male and 5 female patients with an average age of 63.2 years old were included in this study. The median time of removal of the NPWT device was 6 days (ranging from 4 to 7 days). The median amount of drainage fluid within 3 days after surgery was $420 \mathrm{~mL}$ (ranging from $280-760 \mathrm{~mL}$ ), and the median time for complete wound healing was 12 days (ranging from 10 to 21 days).

Conclusion: The results of this study suggest that the modification of NPWT provides various advantages and leads to excellent clinical outcomes in the treatment of severe deep fascial space infections. Future studies will focus on the safety verification of portable usage and the cost effectiveness analysis of NPWT.

Keywords: negative pressure wound therapy, severe deep fascial space infections, modified usage, head and neck

\section{Introduction}

Fascial spaces in the head and neck are fascia-lined tissue compartments filled with loose, areolar connective tissues. In some circumstances, infections arising from the teeth or tonsils can tend to spread into these spaces, in which the cushioning and lubricating tissues become greatly edematous in response to the exudation of tissue fluid. Ultimately, liquefactive necrosis in white blood cells as well as the presence of this connective tissue leads to abscess formation, and surgical incision and drainage are typically needed to resolve the abscess. ${ }^{1}$ Despite the strong advances in antibiotics and critical care medicine over the past decades, highly severe 
infections of deep fascial spaces can directly compress or deviate the airway which can lead to death, ${ }^{2}$ or it can damage vital organs such as the brain, heart, lungs, or skin.

The standard treatment for deep fascial space infections consists of medical support for the patient, surgical drainage of the infection and administration of correct antibiotics. $^{3}$ Among these modalities, wide surgical debridement and thorough drainage are crucial for decreasing the mortality rate. ${ }^{4}$ Usually, one or more drains are required to provide adequate drainage and decompression of the infected area. However, traditional wide debridement and drainage result in several problems, including the limited selection of incision sites due to gravity drainage, daily irrigation and dressing changes accompanied by painful patient experience, tremendous invasive secondary tissue trauma, secondary infection and cosmetic changes in the face and neck. ${ }^{5}$ Therefore, it is necessary to modify the methodology and raise the efficiency of wound care in the surgical management of fascial space infections.

Negative pressure wound therapy (NPWT) is an alternative type of dressing, that consists of a computercontrolled therapy unit, canister, sterile plastic tubing, foam dressing, and clear drape dressing. This device creates a partial vacuum using suction and removes blood and fluid that may collect in the wound. The vacuum may also help draw together wound edges, increase blood flow, and encourage the formation of granulation tissue. ${ }^{6}$ The application of the NPWT system seemed to be an attractive option in wound care, and there have been several reports on its successful usage in the treatment of necrotizing fasciitis, ${ }^{7}$ open fracture wounds, ${ }^{8}$ split-thickness skin grafts and so on. ${ }^{9}$ However, due to the consideration of the multiple and deep tunnels of the fascial spaces, surgeons may be concerned about inadequate suction at the distal end of the spaces if the foam dressing is not placed at the appropriate depth, blockage of the foam dressing if the infectious materials are too thick, or adhesion of the foam dressing to the tissue if it is placed too deeply into the spaces. This substantially hampers the utilization of NPWT in the management of deep fascial space infections. To our knowledge, there have been few detailed reports on NPWT use for severe deep fascial space infections in the maxillofacial surgery literature. To address this problem, we designed a new, modified NPWT that is comprised of the traditional drainage tube and the NPWT for the treatment of severe deep fascial space infections. This new combination allows patent drainage of multiple deep spaces, reduces tube insertion procedures and alleviates pain in patients. To our knowledge, the existing literature offers little clinical experience on NPWT for dealing with severe deep fascial space infections in the head and neck. The purpose of this article is to present our experience, describe the detailed usage of the modified NPWT strategy and retrospectively investigate the clinical efficacy of this system in a consecutive case series of severe deep fascial space infections in the head and neck region.

\section{Materials and Methods}

Due to the retrospective nature of this study, it was granted an exemption in writing by the Institutional Review Board of 940th Hospital of the People's Liberation Army of China. We have read the Helsinki Declaration and have followed the guidelines in this investigation. The patient data were anonymized and maintained with confidentiality. From 2016 to 2018, we treated 12 patients with severe deep fascial space infections in the head and neck with the use of NPWT. Patients who had abscess formation in two or more deep spaces in the head and neck and who had a direct threat to the airway were included in this retrospective study. Patients with necrotizing fasciitis (NF) in the head and neck were excluded since the usage of NPWT in NF patients is different from the modified method in this study. The involved spaces were recorded and summarized. The diagnoses were based on patients' clinical history and presentations and were confirmed by computed tomography findings. The medical conditions of the patients were evaluated, and symptomatic treatments such as oxygen supplementation were given immediately after admission. Routine physical examinations, including oral and tonsil examination, skin inspection and palpation of the abscess and laboratory tests were performed. Intravenous broad-spectrum antibiotics, consisting mainly of $\beta$-lactams such as ceftriaxone, were administered. Surgical drainage under general anesthesia were performed.

\section{Surgical Procedures}

Patients underwent extraoral surgical incision and drainage under general anesthesia with intubation. For those patients with a difficult airway due to severe swelling of the neck, aspiration of the pterygomandibular, lateral pharyngeal, submandibular, or sublingual space abscesses was performed with a large-bore needle under local anesthesia in order to decompress the surrounding tissues. Before the actual incision of the abscess was performed, a specimen 
was acquired for culture and antibiotic sensitivity testing. Incisions were carefully selected to facilitate drainage and avoid damaging vital structures. Blunt dissection was performed without direct exposure or visualization of the entire infected anatomic space using the beaks of a hemostat or the fingers until pus was found. The necrotic tissue was removed, and the wound was rinsed thoroughly. To pass a drainage tube through multiple spaces, a large curved hemostat was used to insert the drainage tube from one incision to another. A latex drainage tube was then grasped with the tip of the hemostat and pulled through the dissected pathway to form a through-and-through drain (Figure 1). After the placement of traditional drainage tubes, the NPWT device was applied. First, we cut the foam materials into bar-shaped pieces and inserted them into the wound along with the latex drainage tubes (Figure 2). The foam was placed into the wound at a depth of approximately half of the incision tunnel to achieve suitable negative pressure in the tunnel. Theoretically, the negative pressure would also be acquired in the tip of the tunnel through the holes of the latex drainage tubes. Second, a block of foam dressing was

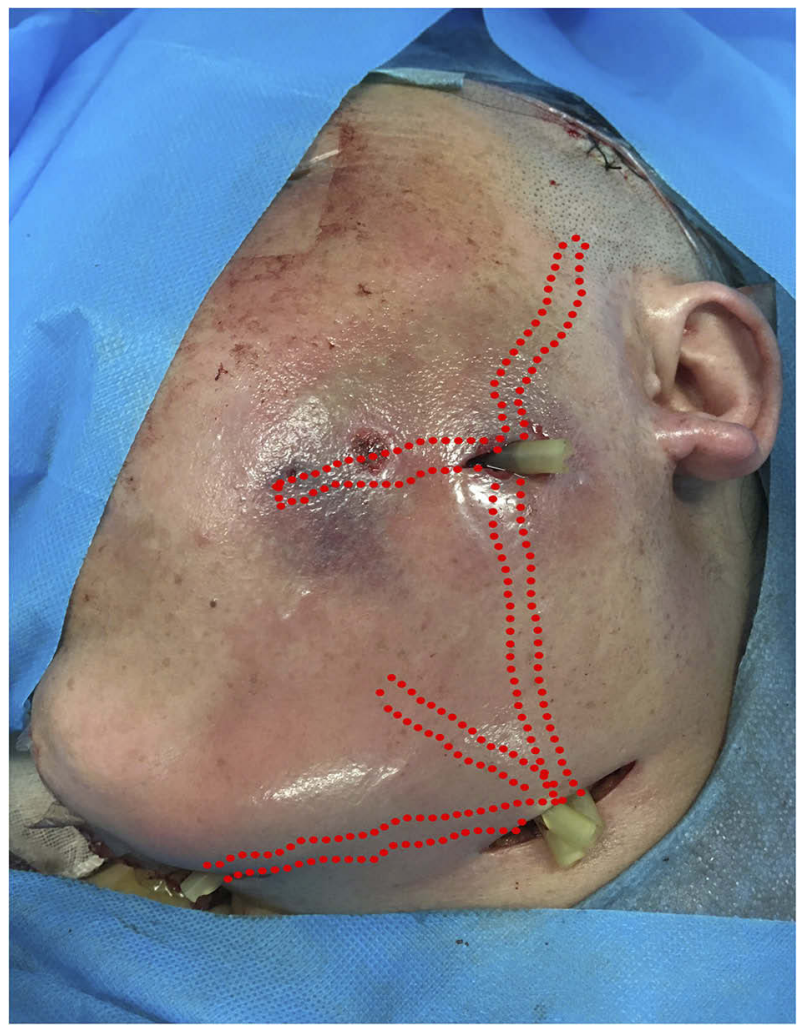

Figure I The latex drainage tubes were inserted into the wound. Note that the red lines indicate the direction and depth of the latex side-holed drainage tubes, some of which were pulled through the dissected pathway to form a through-andthrough drain.

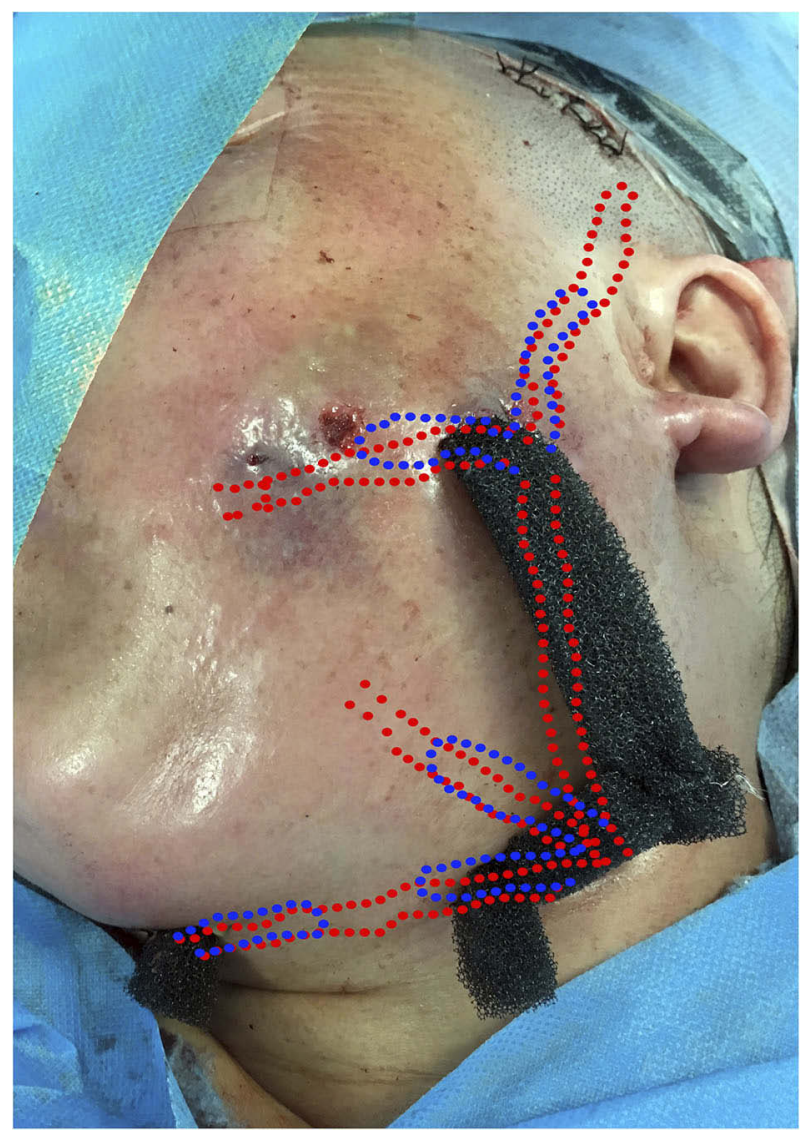

Figure 2 The foam materials were cut into bar-shaped pieces and inserted into the wound along with the latex drainage tubes. Note that the blue lines indicate the direction and depth of the foam.

placed on the surface of the face and neck to connect all the branches of the bar-shaped foam (Figure 3). Third, a film dressing was applied carefully to seal the foam and wound. Then, a drainage tube was connected to the foam dressing with a vacuum source (Smith \& Nephew, Watford, United Kingdom), and 120-140 mmHg of negative pressure was applied to the wound in continuous suction mode (Figure 4). The patients were admitted to the intensive care unit after the surgery, where the patient's airways were continually monitored, antibiotics were administered intravenously, and the systemic condition was re-evaluated.

\section{Wound Care After Surgery}

Postoperatively, negative pressure was set at a $120-140$ mmHg level of suction in continuous suction mode with no irrigation applied. The container of the NPWT device was replaced once it was almost full (Figure 5). The seal of the membrane was checked routinely. After extubation, the patients were shifted to their wards and the diet was encouraged. The NPWT device was removed on days 5 to 7 based 


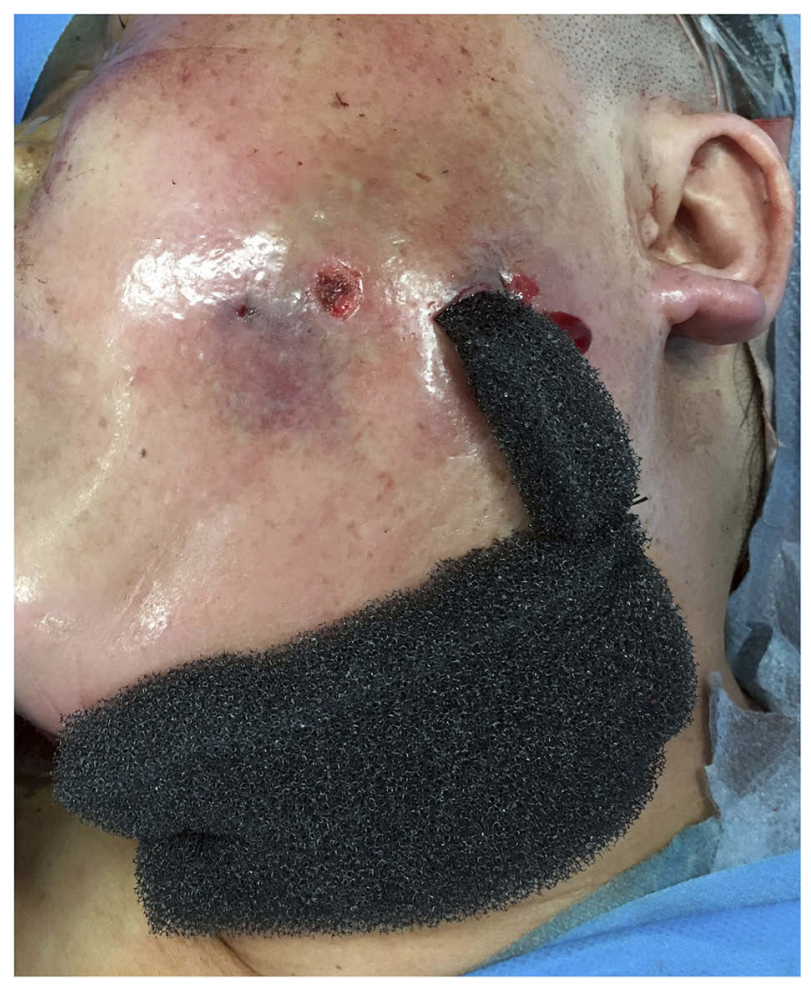

Figure 3 The bar-shaped foam materials were connected by a block of foam dressing on the surface of the face and neck. Sutures were sometimes needed to stabilize the foam block.

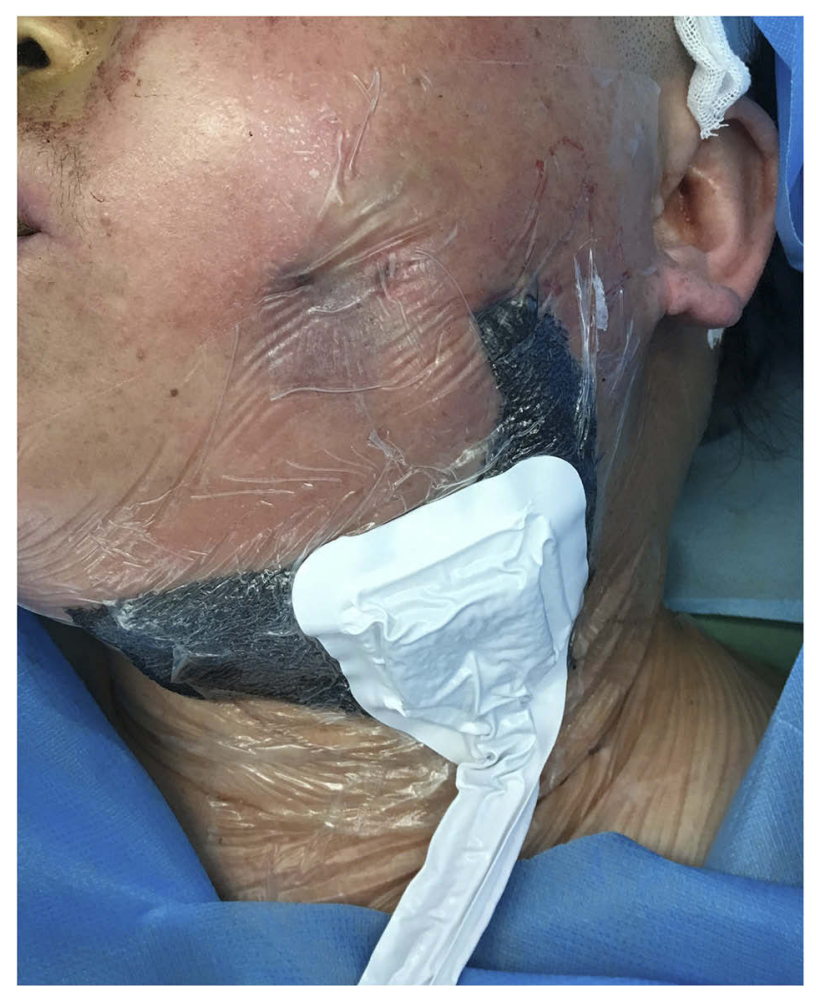

Figure 4 After the application of the film, an adhesive disc and drainage tube were connected to the foam dressing with a pressure-controlled vacuum source.

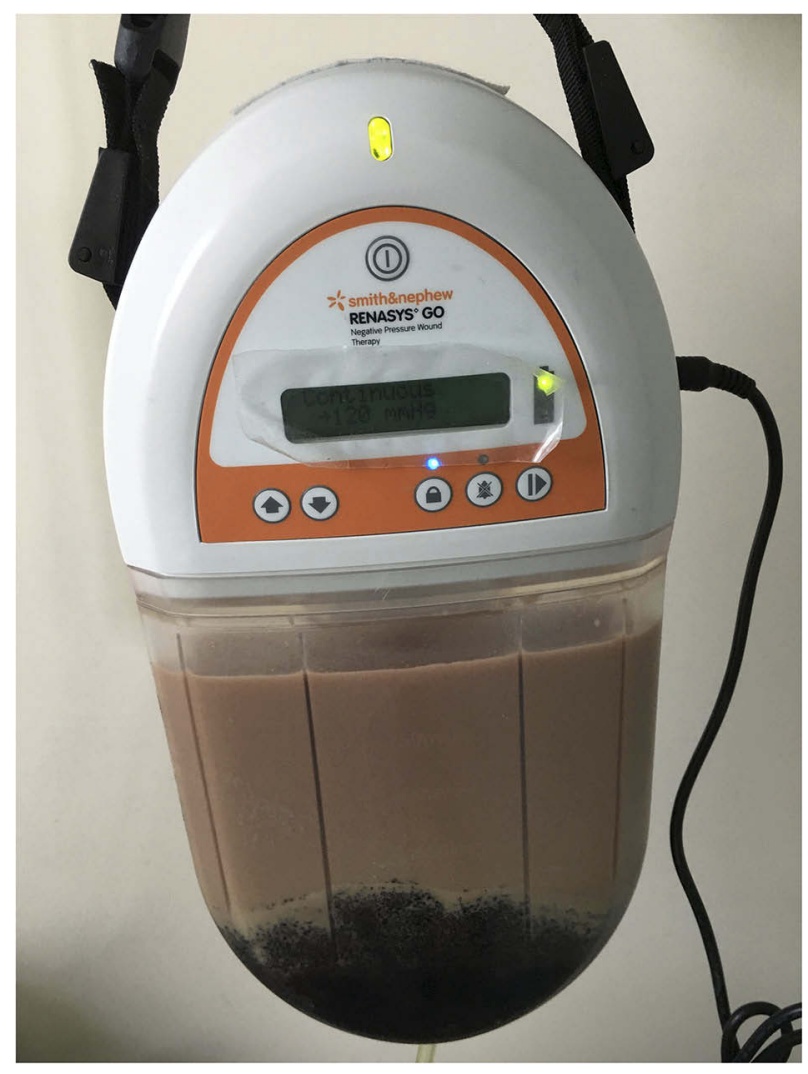

Figure 5 The drainage was efficient and the container of the NPWT device needed to be replaced once it was almost full.

on the condition of the infection and the amount of drainage fluid. The latex drainage tubes were left in the wound for an extra 2-3 days and the dressings were changed daily. Once drainage ceased, drainage tubes were removed gradually to allow wound closure. Antibiotics were administered according to culture and sensitivity testing until the interleukin-6 (IL-6) and procalcitonin (PCT) levels were in a normal range. The demography of the patients and the average healing time were investigated.

\section{Results}

There were 12 patients included in this study, among whom were 7 men and 5 women, with an average age of 62.8 years old (ranging from 35 to 79 years). The demographics and clinical characteristics of the patients are summarized in Table 1. Overall, three of these patients had diabetes mellitus, and one of these patients had a two-year history of prednisone intake because of rheumatoid arthritis. These patients were treated according to the consultation with the physician, including insulin therapy and corticosteroid withdrawal. Ten of these patients had odontogenic infections, while the 
Table I The Demographics and Clinical Characteristics of the Patients

\begin{tabular}{|c|c|c|c|c|c|c|}
\hline $\begin{array}{l}\text { Patient } \\
\text { No. }\end{array}$ & Sex & $\begin{array}{l}\text { Age } \\
\text { (Years) }\end{array}$ & $\begin{array}{l}\text { Source of } \\
\text { Infection }\end{array}$ & $\begin{array}{l}\text { Associated } \\
\text { Diseases }\end{array}$ & Involved Spaces & Bacterial Findings \\
\hline 1 & Female & 57 & Odontogenic & Diabetes mellitus & $\begin{array}{l}\text { Submandibular, submental, buccal, deep temporal, } \\
\text { superficial temporal, pterygomandibular, } \\
\text { submasseteric, lateral pharyngeal }\end{array}$ & Streptococcus viridans \\
\hline 2 & Male & 46 & Odontogenic & - & $\begin{array}{l}\text { Submandibular, buccal, pterygomandibular, } \\
\text { submasseteric, lateral pharyngeal }\end{array}$ & - \\
\hline 3 & Male & 59 & Tonsil & - & $\begin{array}{l}\text { Submandibular, sublingual, submental, lateral } \\
\text { pharyngeal, pretracheal }\end{array}$ & Streptococcus viridans \\
\hline 4 & Male & 68 & Odontogenic & $\begin{array}{l}\text { Rheumatoid } \\
\text { arthritis and } \\
\text { prednisone history }\end{array}$ & $\begin{array}{l}\text { Sublingual, submental, deep temporal, } \\
\text { pterygomandibular, lateral pharyngeal, pretracheal }\end{array}$ & $\begin{array}{l}\text { Streptococcus } \\
\text { pneumoniae }\end{array}$ \\
\hline 5 & Female & 79 & Odontogenic & Diabetes mellitus & $\begin{array}{l}\text { Submandibular, deep temporal, superficial } \\
\text { temporal, pterygomandibular, submasseteric, } \\
\text { lateral pharyngeal }\end{array}$ & Streptococcus viridans \\
\hline 6 & Female & 72 & Odontogenic & - & $\begin{array}{l}\text { Sublingual, submental, lateral pharyngeal, } \\
\text { pretracheal }\end{array}$ & Streptococcus viridans \\
\hline 7 & Male & 75 & Odontogenic & - & Submandibular, submasseteric, lateral pharyngeal & Staphylococcus aureus \\
\hline 8 & Male & 35 & Odontogenic & - & Submandibular, submental, lateral pharyngeal & $\begin{array}{l}\text { Streptococcus } \\
\text { hemolyticus }\end{array}$ \\
\hline 9 & Male & 73 & Tonsil & Diabetes mellitus & $\begin{array}{l}\text { Buccal, submandibular, submental, deep temporal, } \\
\text { submasseteric, lateral pharyngeal }\end{array}$ & - \\
\hline 10 & Female & 65 & Odontogenic & - & $\begin{array}{l}\text { Submandibular, sublingual, submental, } \\
\text { submasseteric, lateral pharyngeal, }\end{array}$ & Staphylococcus aureus \\
\hline II & Female & 68 & Odontogenic & - & $\begin{array}{l}\text { Submandibular, sublingual, submental, } \\
\text { pterygomandibular, lateral pharyngeal, pretracheal }\end{array}$ & $\begin{array}{l}\text { Streptococcus } \\
\text { hemolyticus }\end{array}$ \\
\hline 12 & Male & 56 & Odontogenic & - & $\begin{array}{l}\text { Sublingual, submental, lateral pharyngeal, } \\
\text { pretracheal }\end{array}$ & - \\
\hline
\end{tabular}

remaining two patients had tonsillar origins. The infected fascial spaces included the submandibular, sublingual, submental, deep temporal, superficial temporal, pterygomandibular, submasseteric, lateral pharyngeal, and pretracheal spaces. Three patients had Ludwig angina with crepitus. The infected spaces were confirmed by both the preoperative $\mathrm{CT}$ scan and the intraoperative findings. Intubation was challenging before surgery and one patient received puncture with a large-bore needle in the sublingual and submandibular spaces before intubation to decompress the swelling around the epiglottis. No tracheotomy was performed in any of the patients.

Bacterial growth on cultures was observed in ten patients, and Streptococcus was the most frequently found bacterium. The median time of removal of the NPWT device was 6 days (ranging from 4 to 7 days). The median amount of drainage fluid within 3 days after surgery was $420 \mathrm{~mL}$ (ranging from $280-760 \mathrm{~mL}$ ). All the patients recovered uneventfully after the removal of the NPWT device, and no secondary debridement or NPWT device replacement was performed (Figure 6). The median time for the administration of antibiotics was 10.5 days (ranging from 8.5 to 16.0 days), and the median time for the complete wound healing was 12.5 days (ranging from 10 to 21 days) (Figure 7).

\section{Discussion}

Infection of the deep fascial spaces of the head and neck can compress, deviate or obstruct the airway, invade vital structures and allow extension of the infection into the mediastinum. The primary principle of management of these infections is to perform surgical drainage for the accumulated pus and necrotic debris. Traditionally, radical incision and debridement, adequate and unobstructed drainage placement, and frequent and daily dressing changes are essential for treatment. However, due to the existence of multiple potential deep spaces and the nature of cellulitis, it takes a rather long time to recover fully. Moreover, daily or twice daily dressing changes and irrigation can be painful for patients and may result in contagion in the hospital. ${ }^{10}$ 


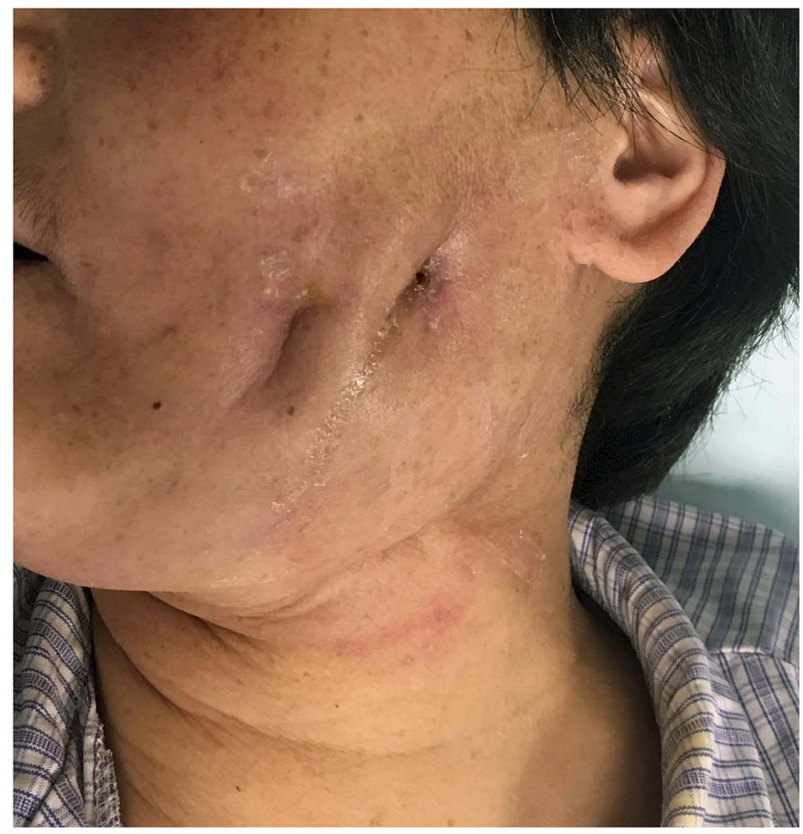

Figure 6 This patient recovered 4 days after the removal of the NPWT device, leaving the scars to be corrected later.

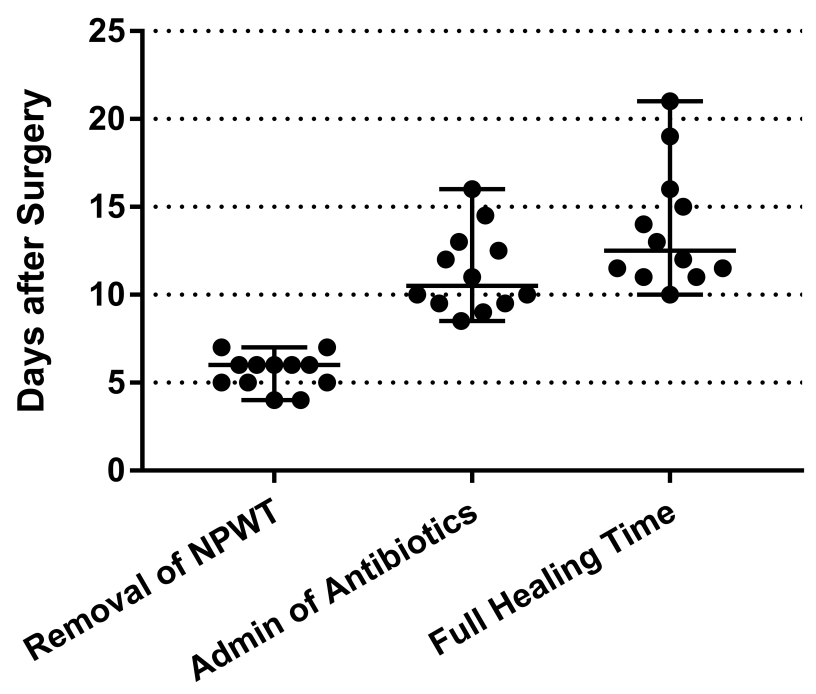

Figure 7 Scatter plot of the time of removal of NPWT, administration of antibiotics, and complete wound healing of all 12 patients. The median time and range are indicated.

NPWT has been widely used in wound care, especially for some complicated wounds such as diabetic foot ulcers. ${ }^{11}$ NPWT involves the use of a drainage device, and it can also reduce edema, increase blood flow, and stimulate the wound healing process by mechanotransduction, moisture control, temperature stabilization, cell recruitment, and cell proliferation. ${ }^{12}$ With the use of NPWT, surgeons can make a smaller incision and do not need to strictly follow the law of gravity drainage. ${ }^{13}$
Furthermore, patients can avoid long periods of painful dressing changes and irrigation after surgery. Although it was difficult to compare the wound healing period between the use of NPWT and traditional drainage because of the uneven baseline values among the patients, we empirically observed a shortening of the recovery period in NPWT patients. The sealing of the wound after surgery could also prevent contamination of pathogenic organisms in the hospital. ${ }^{10}$

The use of NPWT as a surgical adjuvant in maxillofacial surgery was first described in 2006. ${ }^{14}$ However, there are some obstacles with the use of NPWT for the treatment of deep fascial space infections. The first is that the contours of the head and neck make it challenging to obtain an airtight seal for NPWT systems. In our experience, surgeons who receive proper training can perform sealing with preshaped membranes very well. Even in patients with sublingual or lateral pharyngeal space infections, ruptures that occur during surgery on the mucosa of the mouth can be suctioned and closed after the implementation of negative pressure. Second, the deep spaces in the head and neck make the filling of foam material very difficult. Since the foam material is reticulated and porous, the healing tissue can grow into the foam and make removal very difficult if the foam is plugged too deep. ${ }^{15}$ On the other hand, if the foam is not inserted to an appropriate depth, inadequate suction at the distal end of the spaces can lead to the accumulation of pus and debris. To resolve this problem, we designed a new combination of NPWT and a traditional latex drainage tube to achieve a steady negative pressure in the spaces. The half-plugged foam could maintain negative pressure through the side-holed latex drainage tube in the distal part of the spaces and was easy to remove 5-7 days after surgery. In this case series, we removed the NPWT device 6 days (ranging from 4 to 7 days) after surgery, and no retention of the foam occurred. Furthermore, we arranged the foam bar along with the side-holed tube in the spaces and connected all the incisions on the surface of the head and neck with the foam block. This created drainage bypass and avoided the accumulation of pus and debris in the case of blockage in some part of the foam bar. After the removal of the NPWT device, the sideholed latex tube could still be left in the wound for a few days and a second procedure involving the insertion of drainage materials was avoided.

Although it does make clinical sense to remove bacteria, pus, clots, and necrotic tissue from infected wounds by 
irrigation, there is little evidence to indicate that frequent wound irrigation hastens the resolution of infection. Moreover, the NPWT device can remove the fluid continuously and create macrodeformation or shrinkage of the wound, which creates a suitable environment for wound healing. In our experience, irrigation during NPWT may increase the odds of reswelling and interrupt the healing process. In this case series, the median wound healing time was 12 days (ranging from 10 to 21 days). Although the baseline was uneven, it showed a steady decrease compared with the previous traditional treatment in our department (median time 15 days).

According to Food and Drug Administration guidelines, NPWT is contraindicated in exposed vasculature and nerves. ${ }^{16}$ During surgery, we used blunt dissection, protected the carotid sheath carefully, and then applied the foam bar away from the carotid artery. After surgery, $120-140 \mathrm{mmHg}$ of continuous negative pressure was set. The level of negative pressure was set according to the brochure for the NPWT device and was adjusted individually according to the blood pressure of the patients. The continuous mode was set for suction of the purulent and necrotic materials. Additionally, in the case of tracheal wall atresia caused by negative pressure, we also avoided the placement of foam material near the trachea. The patients' airway and drainage fluid were continually monitored, including the color and amount, especially in the 2-3 days after surgery. The median amount of drainage fluid within 3 days after surgery was $420 \mathrm{~mL}$, with purulent discharge and no red arterial blood. Although there have been other reports of serious complications, ${ }^{17}$ we did not encounter any complications associated with NPWT.

Due to the retrospective study nature, there are certain limitations to the study. First, there were no control groups in this study. Second, a cost effectiveness analysis of NPWT was not performed. Taking the shortened healing time and hospital stay into account, it may compensate for the cost of the NPWT device. Third, we restricted patients' activity in the ward for safety during NPWT, although it was not necessary for all patients. It is reasonable for some patients to be discharged from the hospital and return home with the portable NPWT device before the next visit, which will markedly reduce the expenses for the patients and medical insurance. Further research should be conducted in terms of safety verification and cost effectiveness analysis.
In conclusion, the modified NPWT provides various advantages and leads to excellent clinical outcomes in the treatment of severe deep fascial space infections.

\section{Acknowledgments}

This study was supported by Ninth People's Hospital affiliated to Shanghai JiaoTong University, School of Medicine "Multi-Disciplinary Team" Clinical Research Project (2017-1-005), the Integrated Fund Project of Ninth People's Hospital, the Clinical Research Plan of SHDC (16CR3019A), and the Interdisciplinary Program of Shanghai Jiao Tong University (YG2017ZD03).

\section{Author Contributions}

All authors contributed to data analysis, drafting or revising the article, gave final approval of the version to be published, and agree to be accountable for all aspects of the work.

\section{Disclosure}

The authors report no conflicts of interest in this work.

\section{References}

1. Storoe W, Haug RH, Lillich TT. The changing face of odontogenic infections. J Oral Maxillofac Surg. 2001;59(7):739-748. doi:10.105 3/joms.2001.24285

2. Aziz N, Shah TH, Saeed T, Khan P. Prediction of difficult tracheal intubation. J Med Sci. 2010;18(3):135-139.

3. Flynn TR, Shanti RM, Levi MH, Adamo AK, Kraut RA, Trieger N. Severe odontogenic infections, part 1: prospective report. J Oral Maxillofac Surg. 2006;64(7):1093-1103. doi:10.1016/j.joms.2006.03.015

4. Flynn TR. Surgical management of orofacial infections. Atlas Oral Maxillofac Surg Clin North Am. 2000;8(1):77-100. doi:10.1016/ S1061-3315(18)30043-X

5. Lawrence R, Bateman N. Controversies in the management of deep neck space infection in children: an evidence-based review. Clin Otolaryngol. 2017;42(1):156-163. doi:10.1111/coa.2017.42.issue-1

6. Gupta S, Gabriel A, Lantis J, Téot L. Clinical recommendations and practical guide for negative pressure wound therapy with instillation. Int Wound J. 2016;13(2):159-174. doi:10.1111/iwj.2016.13.issue-2

7. Chen SJ, Chen YX, Xiao JR, Wei XZ, Chen SM, Jiang WZ. Negative pressure wound therapy in necrotizing fasciitis of the head and neck. J Oral Maxillofac Surg. 2019;77(1):87-92. doi:10.1016/j.joms.2018. 08.016

8. Costa ML, Achten J, Bruce J, et al. Effect of Negative pressure wound therapy vs standard wound management on 12-month disability among adults with severe open fracture of the lower limb the WOLLF randomized clinical trial. JAMA. 2018;319(22):2280-2288. doi:10.1001/jama.2018.6452

9. Zhang DM, Yang ZH, Zhuang PL, Wang YY, Chen WL, Zhang B. Role of negative-pressure wound therapy in the management of submandibular fistula after reconstruction for osteoradionecrosis J Oral Maxillofac Surg. 2016;74(2):401-405. doi:10.1016/j.joms.20 15.09.012

10. Dellinger EP. Prevention of hospital-acquired infections. Surg Infect (Larchmt). 2016;17(4):422-426. doi:10.1089/sur.2016.048 
11. Dale AP, Saeed K. Novel negative pressure wound therapy with instillation and the management of diabetic foot infections. Curr Opin Infect Dis. 2015;28(2):151-157. doi:10.1097/QCO.0000000000000146

12. Byrnside V, Glasgow M, Gurunluoglu R. The vacuum-assisted closure in treating craniofacial wounds. J Oral Maxillofac Surg. 2010;68 (4):935-942. doi:10.1016/j.joms.2009.09.113

13. Venturi ML, Attinger CE, Mesbahi AN, Hess CL, Graw KS. Mechanisms and clinical applications of the vacuum-assisted closure (VAC) device: a review. Am J Clin Dermatol. 2005;6(3):185-194. doi:10.2165/00128071-200506030-00005

14. Schuster R, Moradzadeh A, Waxman K. The use of vacuum-assisted closure therapy for the treatment of a large infected facial wound. $\mathrm{Am}$ Surg. 2006;72(2):129-131.
15. Loaec E, Vaillant PY, Bonne L, Marianowski R. Negative-pressure wound therapy for the treatment of pharyngocutaneous fistula. Eur Ann Otorhinolaryngol Head Neck Dis. 2014;131(6):351-355. doi:10. 1016/j.anorl.2013.12.001

16. Anesäter E, Borgquist $\mathrm{O}$, Torbrand $\mathrm{C}$, et al. The use of a rigid disc to protect exposed structures in wounds treated with negative pressure wound therapy: effects on wound bed pressure and microvascular blood flow. Wound Repair Regen. 2012;20(4):611-616. doi:10.1111/j.1524475X.2012.00801.x

17. Li Z, Yu A. Complications of negative pressure wound therapy: a mini review. Wound Repair Regen. 2014;22(4):457-461. doi:10.1111/wrr.201 4.22.issue- 4

\section{Publish your work in this journal}

Infection and Drug Resistance is an international, peer-reviewed openaccess journal that focuses on the optimal treatment of infection (bacterial, fungal and viral) and the development and institution of preventive strategies to minimize the development and spread of resistance. The journal is specifically concerned with the epidemiology of antibiotic resistance and the mechanisms of resistance development and diffusion in both hospitals and the community. The manuscript management system is completely online and includes a very quick and fair peerreview system, which is all easy to use. Visit http://www.dovepress.com/ testimonials.php to read real quotes from published authors. 